\title{
Impacts on High-level Systems-of-Systems Figures of Merit due to Integrated Architecture Sizing and Technology Evaluation at the Subsystem-Level
}

\author{
Douglas J. Trent* and Dimitri N. Mavris ${ }^{\dagger}$ \\ Aerospace Systems Design Laboratory, Georgia Institute of Technology, Atlanta, GA 30332
}

\begin{abstract}
Understanding the impacts on high-level system-of-systems (SOS) figures of merit (FOMs) due to the design of architectures and technologies is critical in providing decision makers sufficient information in selecting suitable alternatives in an effort to reduce costly financial and schedule overruns. Several techniques exist within academia and industry for performing SOS architecture design and technology evaluation. However, these techniques fail to solve the problem in an integrated fashion when defined at the subsystem-level. In order to understand the impacts on high-level SOS FOMs due to integrated architecture sizing and technology evaluation, a general concept exploration process is utilized to perform a notional 2033 manned Mars fly by study. The notional study draws out observation with regard to specific FOMs traditionally used during the subsystem-level sizing and technology evaluation processes which can result in misleading conclusions regarding the overall SOS design. Furthermore, these observations suggest that selection of FOMs for the subsystems of an architecture should be influenced by the desired objectives of the high-level SOS objectives and FOMs.
\end{abstract}

\section{Nomenclature}

$D Y R E Q T=$ Dynamic Rocket Equation Tool

FOM = figure of merit

$M O A=$ Matrix of Alternatives

$P M F \quad=$ Propellant Mass Fraction

$Q F D \quad=$ Quality Function Deployment

$R T G \quad=$ Radioisotope Thermoelectric Generator

SLS $\quad=$ Space Launch System

$\mathrm{SOS} \quad=$ System of Systems

TOPSIS = Technique for Order Preferencing by Similarity to Ideal Solution

\section{Introduction}

$\mathrm{D}$ ECISIONS made early in the design process have disproportionate impacts on the future cost and schedule of corresponding programs. It is important to understand the interaction of the mission, the vehicle, and technologies on a given architecture to ensure that a suitable alternative is selected to prevent costly financial and schedule overruns. This section will provides the motivation behind integrating architecture sizing and technology evaluation at the subsystem-level. This section will also help clarify the implied meaning for several terms that are regularly used within the space architecting community for the purposes of this paper.

\section{A. Motivation}

The task of designing complex architectures is by no means trivial. To do so with such political instability and uncertainty in todays environment presents increased challenges to designers. Through the course of the design phases, there are several concepts that must be weighed: cost, design knowledge, and design freedom. Contrary to traditional

\footnotetext{
*Aerospace Engineer, Advanced Concepts Office, NASA/MSFC ED04, Huntsville, AL 35812, AIAA Member, work performed during tenure as a Georgia Tech ASDL graduate student

${ }_{\dagger}^{\dagger}$ S.P. Langley Distinguished Regents Professor and Director of ASDL, 270 Ferst Dr. NW, Mail Stop 0150, AIAA Fellow.
} 


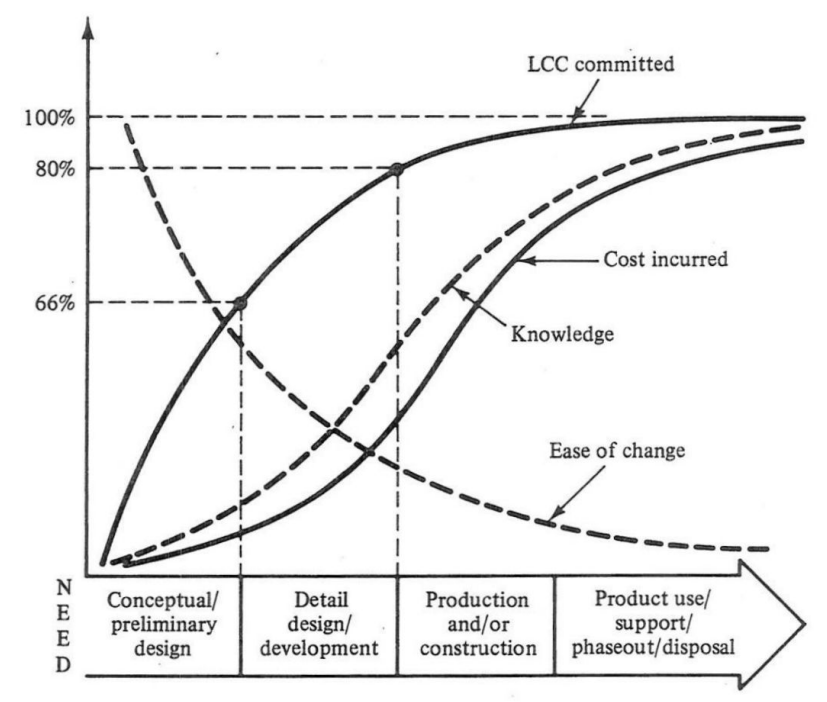

Fig. 1 Cost and Knowledge Curves in the Design Life Cycle [1]

thought, cost is not incurred at the time committed, but rather through the process of making design decisions [1]. Decisions about the design tend to be made early in the design process. This means that a majority of the cost for a design is committed very early in the design process, while that cost is not incurred until later in the design process. Many studies have examined this behavior. One such study determined that only $20 \%$ of the cost is incurred during the early phases of design, while those same phases commit $80 \%$ of the cost [2]. Fig. 1]illustrates this relationship between cost, ease of change, and design knowledge. Here, ease of change can be interpreted as a measure of design freedom.

Typically, design decisions are made early in the design process, when knowledge is relatively low. This can result in uninformed decisions that can lead to costly design revisions in later phases, particularly during testing. A good example of this behavior is in the development of liquid rocket engines. Glen Havskjold performed a study on historical development programs from the Pratt \& Whitney Rocketdyne Company [3-5]. Due to a lack of design knowledge during the initial design phase of these engines, a pattern of test-fail-fix occurs during the development and testing. The result is increased costs and schedule of the engines studied. In fact, $73 \%$ of the development cost of the F-1, J-2, and Space Shuttle Main Engine were determined to be due to corrective actions during full-scale testing [3]. Further more, NASA's System Engineering Handbook states that restrictive requirements will result in limited potential design alternatives [6].

These relationships between design knowledge, design freedom, and cost, indicate the need for well-informed decisions early in the design process. These decisions are vital to reducing the risk of increased cost and schedule due to design iterations [7]. Industry and academia have been working towards this goal through various means [8-12]. These methods share similar techniques of bringing design knowledge earlier into the design process in an attempt to maintain design freedom longer while allowing decision makers to make informed decisions about the design, leading to reduced cost and schedule.

\section{B. Definitions}

It is important to take a moment to define the concepts that exist in the realm of space systems design. Many readers will be familiar with the terms system, , vehicle, mission, technology, architecture, and campaign. There may exist several accepted definitions for a term. In these instances, the implied definition for these terms throughout the remainder of this document shall be those presented in this section.

\section{System}

Several definitions exist for the term system, originating from several domains such as defense, civil aerospace, academia, and various regulatory organizations. However, these entities all have common themes which constitute a system, [6, 9, 13,-15]:

- A thoughtful, organized assembly of elements 
- Regular interaction and interdependence between elements

- Elements can be products, processes, people, information, techniques, facilities, services, and other support elements

- Elements are brought together to achieve some stated purpose that is otherwise unattainable by the individual elements

Considering these key commonalities, a system shall be considered an organized set of regularly interacting and interdependent products, processes, people, information, techniques, facilities, services, and other support elements, collectively known as subsystems, brought together for a stated purpose otherwise unattainable. Also, note that this definition for a system also inherently defines the terms subsystem as the all inclusive set of all interacting things that make up a system.

\section{System of Systems}

The term system-of-systems (SOS) has come to mean a variety of things within professional and academic disciplines. Generally, they conform to similar concepts, but different definitions provide specific details. Combining this information, a system-of-systems exhibits the following characteristics:

- Component systems have a level of independence from each other and are autonomous [16]

- Component systems are not necessarily defined by being included in a system-of-systems but do work together for the purpose of the system-of-systems [17]

- System of systems typically aim to solve large-scale interdisciplinary problems often consisting of non-linear effects [15, 18]

With this knowledge, a system-of-systems shall be considered a set of systems that results when independent and useful systems are integrated to deliver unique capabilities typically for the purpose of solving large-scale interdisciplinary problems. Though the component systems are not necessarily defined by the SOS, space flight situations typically lead to component systems that are highly specialized and designed for a given SOS problem. This can be attributed to extremely unique operational environments, coupled with labor-intensive designs [19].

\section{Technology}

NASA defines a technology as "A solution that arises from applying the discipline of engineering science to synthesize a device, process, or subsystem, to enable a specific capability" [20]. This shall be the implied meaning of a technology for this discussion. The definition implies that a technology is considered at the device or subsystem-level. This distinction is important when it comes to defining trade spaces and physically evaluating candidate solutions to a problem. Several organization have created scales to evaluate the development status of a technology. One such scale is NASA's technology readiness level. For details regarding the definition of the various level of technology readiness, refer to NASA's System Engineering Handbook (rev. 2), Figure G.4-1 [6] and NASA's system engineering processes and requirements, NPR 7123, Appendix E [21].

\section{Vehicle}

A vehicle is a structure, machine, or device designed to carry a burden, also known as a payload [22]. The term spacecraft is typically used to denote a vehicle designed specifically for use in space. Within the aerospace community a vehicle is typically divided into eight subsystem [23]:

1) Orbital Mechanics

2) Structures

3) Propulsion

4) Power

5) Thermal Control

6) Attitude Control

7) Command \& Data Handling

8) Telecommunications

\section{Mission}

A mission shall be defined as a task, together with a purpose, that clearly indicates the actions to be taken and the reason therefore [13, 24]. Charles Brown states that space missions are defined to provide one or more of the following 
Table 1 Common Space Architecture Elements [25]

\begin{tabular}{|c|c|}
\hline Element Name & Examples \\
\hline Operations Elements & $\begin{array}{l}\text { - Communication Operations Concepts } \\
\text { - Operations Functions } \\
\text { - Space Logistics } \\
\text { - Command, Control, and Communication }\end{array}$ \\
\hline Orbits and Trajectories & $\begin{array}{l}\text { - Earth Orbits } \\
\text { - Interplanetary Transfers } \\
\text { - Planetary Orbits } \\
\text { - Entry, Descent, Landing, and Ascent }\end{array}$ \\
\hline Transportation Elements & $\begin{array}{l}\text { - Earth-to-Orbit Vehicle } \\
\text { - Launch Facilities }\end{array}$ \\
\hline Space Elements & $\begin{array}{l}\text { - In-Space Vehicle } \\
\text { - Vehicle for Entry, Descent, Landing, and Ascent }\end{array}$ \\
\hline Surface Elements & $\begin{array}{l}\text { - Surface Bases } \\
\text { - Surface Vehicles } \\
\text { - In-Situ Resources }\end{array}$ \\
\hline $\begin{array}{l}\text { Crew } \\
\text { Manned Only }\end{array}$ & $\begin{array}{l}\text { - People as Payload or Operators } \\
\text { - Physiology and Psychology } \\
\text { - Human Factors } \\
\text { - Safety and Reliability }\end{array}$ \\
\hline
\end{tabular}

seven services [23]:

- Communication

- Navigation

- Weather

- Earth Resources

- Astronomy

- Planetary Exploration

- Manned Spaceflight

These services which provide the purpose of a mission are typically achieved through a set of tasks such as data transfers, orbital maneuvers, trajectories, and other vehicle operations.

\section{Architecture}

An architecture shall be defined as the fundamental organization of a system, embodied in its components, their relationships to each other and the environment, the principles governing its design and evolution, its purpose, and its attractiveness [17]. Larson and Pranke state that a mission concept, along with the functional and physical elements defined by this concept, form the basis of the space architecture [25]. These are summarized in Table [1] The relationship between an architecture and the concepts of a vehicle, mission, and technologies and how they fall within the definitions of a subsystem, system, and system-of-systems is depicted by Fig. 2

\section{General Concept Exploration}

The task of performing SOS design through subsystem-level sizing and technology evaluation can be a challenging task. Many methods exist for the purpose of architecture design and technology evaluation. However, there is limited research on performing these task in an integrated fashion when the architectures and technologies are defined at the subsystem-level, as described in the previous section. This section will describes a general concept exploration process which will be utilized to perform a notional space architecture trade study to draw out observation regarding impacts on high-level SOS FOMs due to integrated subsystem-level architecture sizing and technology evaluation. Many models and methods exist in literature for the purpose of concept exploration and refinement. Each are unique and vary in details, but as defined by the United States Air Force, they follow three major steps which will be described in this 


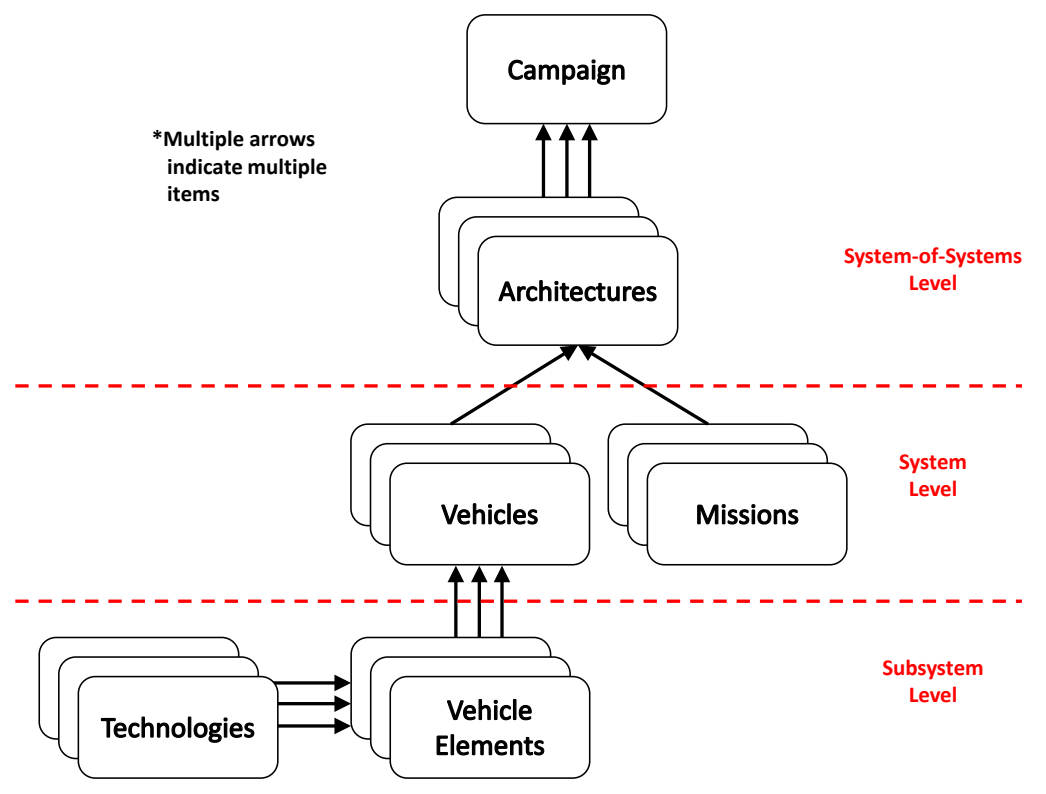

Fig. 2 Space Architecture Terminology Relationships

section [26]:

- Trade space characterization

- Candidate solution sets characterization

- Analysis

\section{A. Phase I: Trade Space Characterization}

The first of the three major steps in concept exploration consist of trade space characterization through definition and decomposition of the problem. This will provide insight into the relationships which exist between architecture alternatives. The following system spaces are utilized to define a problem:

- Architecture Space: the set of potential physical and functional options which exist to solve the problem

- Technology Space: the set of potential subsystem-level items to be considered

- Objective Space: an n-dimensional space consisting of a collection of metrics, or FOMs, which define the overall "goodness" of a design

- Design Space: all design attributes and their feasible ranges

Morphological analysis is a leading technique for decomposing problems which have minimal design knowledge, such as those during the early phases of design [27]. Through morphological decomposition, the architecture and technology spaces are defined which consists of the potential discrete options that exist as a collection of parameters, along with options within each parameter. A matrix of alternatives (MOA) is typically used to represent the options within the various parameters. The DoD Architecture Framework provides details on different ways of viewing these potential spaces. These viewpoints, as defined in version 2.0 of the document, provide many different ways of organizing data to facilitate understanding of complex system-of-systems architectures. An example of these viewpoints would be a typical mission concept chart, like that shown by Fig. 3

Value is established for designs based on the metrics chosen as measures of "goodness" of the designs. These metrics, or FOMs, form the objective space of the problem. These FOMs are determined based on the customer's desires and trade studies of interest. However, customer desires are typically expressed in a subjective manner and must be translated into quantifiable engineering metrics. A leading technique for this purpose is quality function deployment (QFD). QFD is a largely graphical technique which captures the customer wants and maps them to defined engineering parameters for the problem [9]. Engineering Design by Georgie Dieter can be referred to for further detail on implementing QFD. This technique is not the only possible solution to translating customer desires into engineering metrics, but is one of the more formal techniques commonly utilized in practice.

The design space typically become known once a modeling and simulation environment has been selected, as these 
design attributes are typically the inputs of an analysis environment. The modeling and simulation environment is selected or developed for the purpose of translating design space attributes into objective space metrics. For example, if one of the objective space metrics is inert mass of the design, a modeling and simulation environment may utilize inputs such as specific impulse, delta-V, and mission duration as design attributes to calculate the inert mass. Obviously, complex systems-of-systems will contain many systems being sized simultaneously with multiple figures of merit in the objective space, requiring much more complex modeling and simulation environments. However, the idea that the modeling and simulation environment acts as the mapping between the design space and the objective space still holds.

\section{B. Phase II: Candidate Solution Sets Characterization}

The second phase of concept exploration requires characterizing candidate solution sets, otherwise known as alternatives. Typically there are two methods of down selecting a large set of alternatives to perform analysis on. The first consist of utilizing subject matter experts to guide the logical selection of alternatives to those likely to perform well based on the desired objective space. The second is to perform a Design of Experiments (DOE) over a the architecture and technology spaces. DOE is a technique by which a set of alternatives is selected to maximize information while minimizing experimental effort [28].

New concerns arise unique to problems at the architecture level. Typically, technology evaluation is performed only after a baseline design is selected, optimized, and determined infeasible or inviable without incorporating new technologies. This paradigm is prevalent in modern methods for architecture analysis and technology evaluation. However, this practice may lead to misleading results. For example, consider the design of a propulsion stage where either sortable propellants or methane may be utilized. Before any technology infusion, the sortable propellant based design will likely be preferred due to its superior resistance to propellant loss during extended mission durations. However, a methane propellant based design with technologies incorporated to mitigate propellant loss for extended mission duration would likely outperform the sortable propellant based alternatives due to increased engine performance.

Scenarios such as the one just described prompt the consideration of technologies prior to architecture down selection to prevent limiting the alternative space of potentially optimal designs [12]. Furthermore, architectures are almost always defied by both ordinal and categorical variable types. A mixed set of design variables are typically understood to require a full factorial DOE over the discrete variables [29]. However, due to the large numbers of alternatives that will exist in the combined architecture and technology spaces, exploring this set of alternatives becomes challenging due to combinatorial explosion, a problem which has yet to be addressed.

\section{Phase III: Analysis}

The final step in the general concept exploration framework consists of analyzing the alternatives. The end results of analysis are numerical values of the figures of merit selected for ranking designs. These figures of merit will help decision makers come to final conclusions regarding the overall design. As was shown in the previous section, large numbers of alternatives exist in such a complex architecture space. Care must be taken to ensure that useful results are observable among large sets of data. Including technologies into the architecture design problem only complicates the presentation of results by creating ever larger numbers of alternatives. Observation of results from numerous perspectives can help to gain insightful information relating high-level architecture and technology decision to certain objective FOMs. Additionally, there exist many structured techniques for the purpose of decision making: technique for order preferencing by similarity to ideal solution (TOPSIS), technology frontier, and resource allocation are a few.

\section{Notional 2033 Crewed Mars Flyby Study}

A notional 2033 crewed Mars flyby study provides a good benchmark for observations of the effects that integrated subsystem-level architecture sizing and technology evaluation may have on high-level SOS FOMs. This is due to large variability in potential architectures for performing a manned Mars flyby as well as the substantial number of new technologies which must be developed to achieve the objective. The notional study will focus primarily on the transit vehicle and associated technologies. This will aid in limiting the total number of alternatives to mitigate issues due to combinatorial explosion. The notional study will follow the general concept exploration phases discussed in the previous section. 


\section{A. Characterizing the Trade Space}

1. Mission Concept and the Objective Space

Table 2 Figures of Merit

\begin{tabular}{|l|ccc|}
\hline Objective Metric & Weight & Target & Units \\
\hline Number of Launches & 0.4 & Minimize & \\
Architecture Gross Mass & 0.1 & Minimize & $\mathrm{mt}$ \\
Gross Vehicle PMF & 0.1 & Maximize & \\
Gross Vehicle Cost & 0.2 & Minimize & MYr \\
Technological Complexity & 0.2 & Minimize & \\
\hline
\end{tabular}

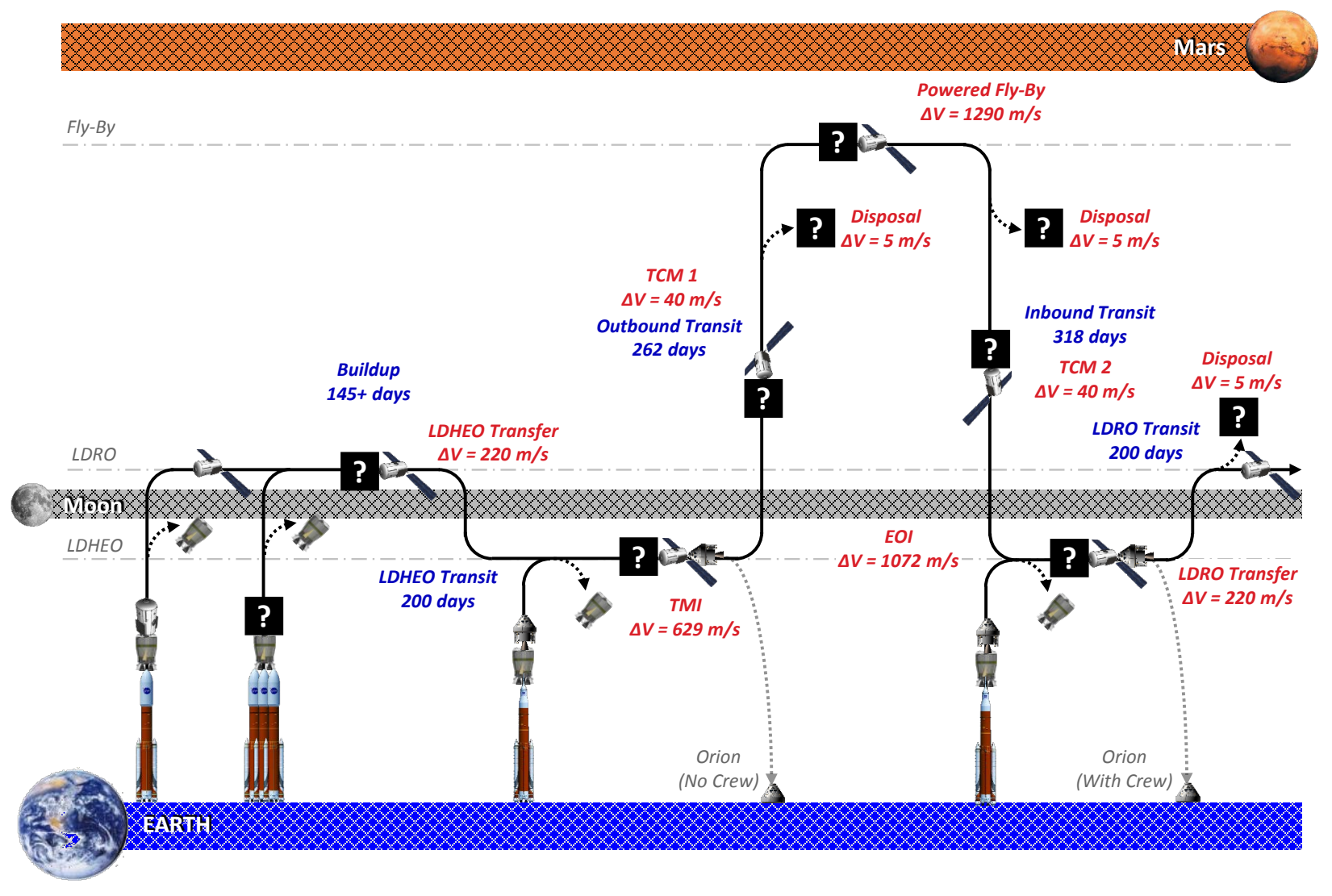

Fig. 3 Mission Concept 
Table 3 Vehicle Subspace Options

\begin{tabular}{|c|c|c|c|c|}
\hline Category & \multicolumn{4}{|c|}{ Options } \\
\hline \multicolumn{5}{|l|}{$\begin{array}{l}\text { Category } \\
\text { Vehicle }\end{array}$} \\
\hline Number of Stages & 1 & 2 & 3 & \\
\hline \multicolumn{5}{|l|}{ Stage(s) } \\
\hline MPS Class & Liquid & Nuclear & & \\
\hline MPS Propellant & $\mathrm{LO}_{2} / \mathrm{LH}_{2}$ & $\mathrm{LO}_{2} / \mathrm{LCH}_{4}$ & $\mathrm{NTO} / \mathrm{MMH} \quad \mathrm{LH}_{2}$ & $\mathrm{~N}_{2} \mathrm{H}_{4}$ \\
\hline RCS Propellant & $\mathrm{LO}_{2} / \mathrm{LCH}_{4}$ & NTO/MMH & $\mathrm{N}_{2} \mathrm{H}_{4}$ & \\
\hline Tank Configuration & Stacked & Disk & Single & \\
\hline Power System & Solar & RTG & & \\
\hline MLI Layers & 10 & 30 & 50 & \\
\hline
\end{tabular}

Table 4 Technology Space Options

\begin{tabular}{|l|cc|}
\hline Category & \multicolumn{2}{|c|}{ Options } \\
\hline Wireless Sensors & TRUE & FALSE \\
Low Leak Valves & TRUE & FALSE \\
High Capacity Energy Storage & TRUE & FALSE \\
Composite Structures & TRUE & FALSE \\
Composite Propellant Tanks & TRUE & FALSE \\
Integrated MPS/RCS Propellant Storage & TRUE & FALSE \\
Autogenous Pressurization & TRUE & FALSE \\
Active Cryocooling & TRUE & FALSE \\
\hline
\end{tabular}

\section{B. Characterizing Candidate Solution Sets}

\section{Modeling and Simulation Environment and the Design Space}

Discussion of DYREQT and the subsystem models used 


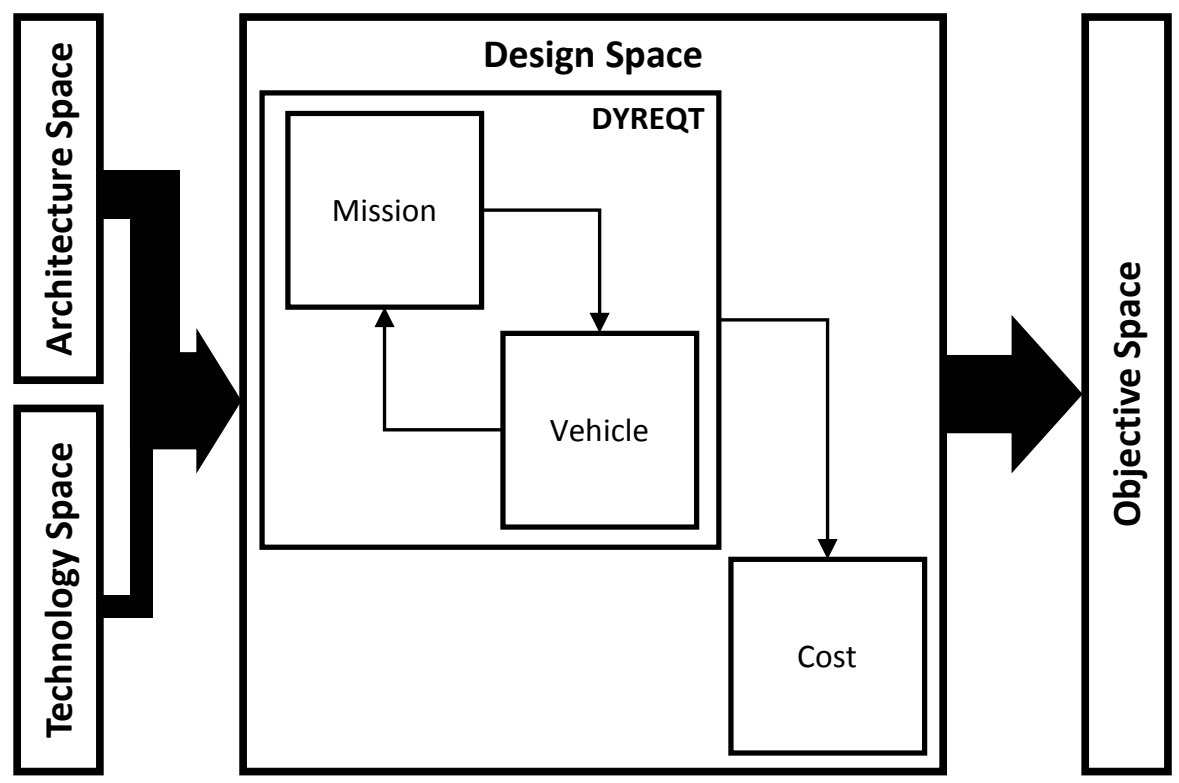

Fig. 4 High-level Mapping of the System Spaces

Table 5 Architecture Space Parameter To Design Space Attribute Mappings

\begin{tabular}{|l|l|}
\hline Architecture Space Parameter & Design Space Attribute(s) \\
\hline Vehicle & \\
\hline Number of Stages & event_list, element_list \\
\hline Stage(s) & \\
\hline MPS Class & event_list, start_penalty_mps, total_thrust_mps, \\
& engine_thrust_mps \\
MPS Propellant & isp_mps, mixture_ratio_mps \\
RCS Propellant & isp_rcs, mixture_ratio_rcs \\
Tank Configuration & num_fuel_tanks_mps, num_ox_tanks_mps \\
Power System & generator_type \\
MLI Layers & mli_layers_mps, mli_layers_rcs \\
\hline
\end{tabular}


Table 6 Technology Space Parameter To Design Space Attribute Mappings

\begin{tabular}{|l|l|}
\hline Technology Space Parameter & Design Space Attribute(s) \\
\hline Wireless Sensors & wireless_sensors \\
Low Leak Valves & start_penalty_mps, start_penalty_rcs \\
High Capacity Energy Storage & storage_specific_energy \\
Composite Structures & composite \\
Composite Propellant Tanks & composite_fuel_tanks_mps, composite_ox_tanks_mps, \\
Integrated MPS/RCS Propellant Storage & composite_fuel_tanks_rcs, composite_ox_tanks_rcs \\
Autogenous Pressurization & ivfm \\
Active Cryocooling & pressurant \\
\hline
\end{tabular}

Table 7 Objective-Design Space Mappings

\begin{tabular}{|l|l|}
\hline Objective Space Metric & Design Space Attribute(s) \\
\hline Number of Launches & $\begin{array}{l}\text { num_stages, total_payload, element(\#)_gross_mass, } \\
\text { element(\#)_burnout_mass } \\
\text { Architecture Gross Mass } \\
\text { vehicle_gross_mass } \\
\text { element(\#)_gross_mass, element(\#)_propellant_mass_mps, } \\
\text { element(\#)_propellant_mass_rcs } \\
\text { vehicle_gross_cost } \\
\text { Gross Vehicle Cost } \\
\text { Technological Complexity } \\
\text { element0_mps_start_penalty, } \\
\text { element0_storage_specific_energy, element0_composites, } \\
\text { element0_composite_fuel_tanks_mps, element0_ivfm, } \\
\text { element0_pressurant, element0_active_cooling_mps, } \\
\text { element0_wireless_sensors }\end{array}$ \\
\hline
\end{tabular}


C. Analysis

1. Observation on the Pareto Front

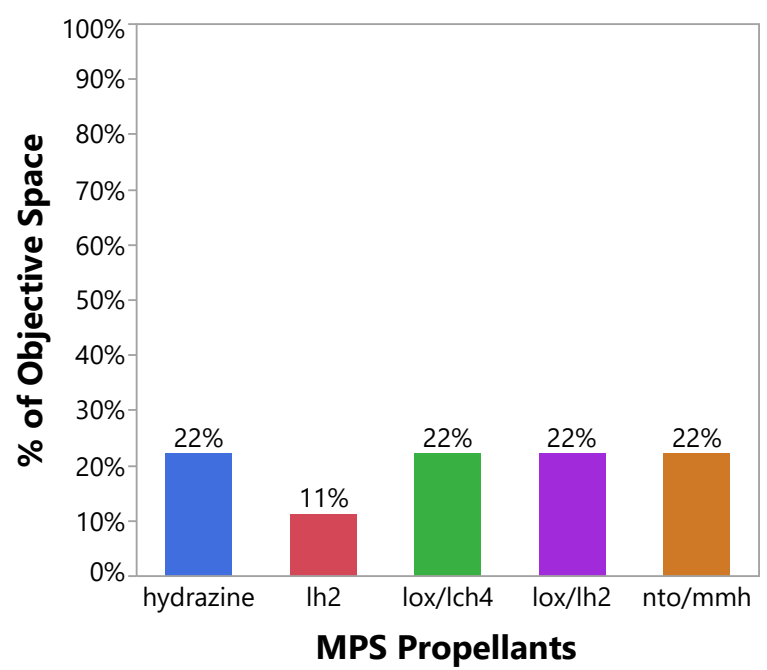

Fig. 5 Objective Space Distribution by Main Propulsion System Propellant Type

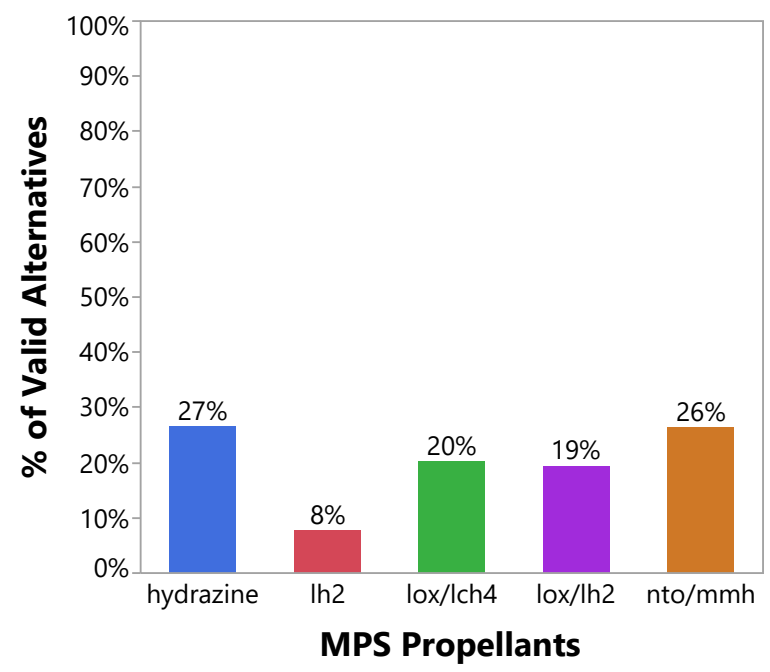

Fig. 7 Valid Alternatives Distribution by Main Propulsion System Propellant Type

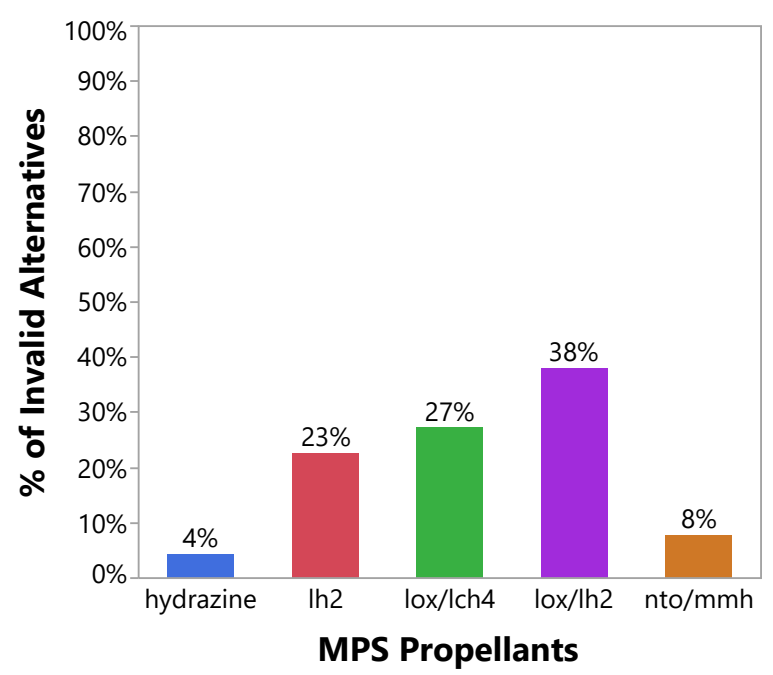

Fig. 6 Invalid Alternatives Distribution by Main Propulsion System Propellant Type

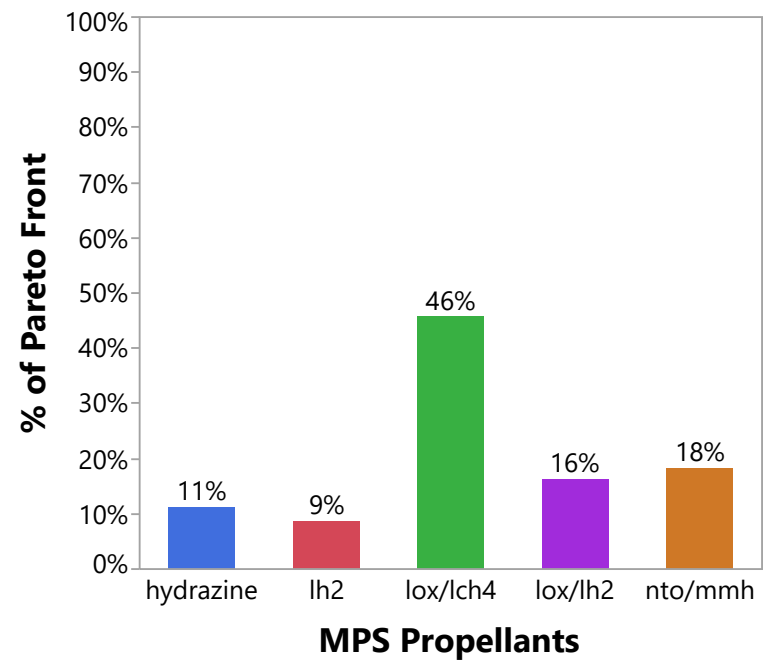

Fig. 8 Pareto Front Alternatives Distribution by Main Propulsion System Propellant Type 


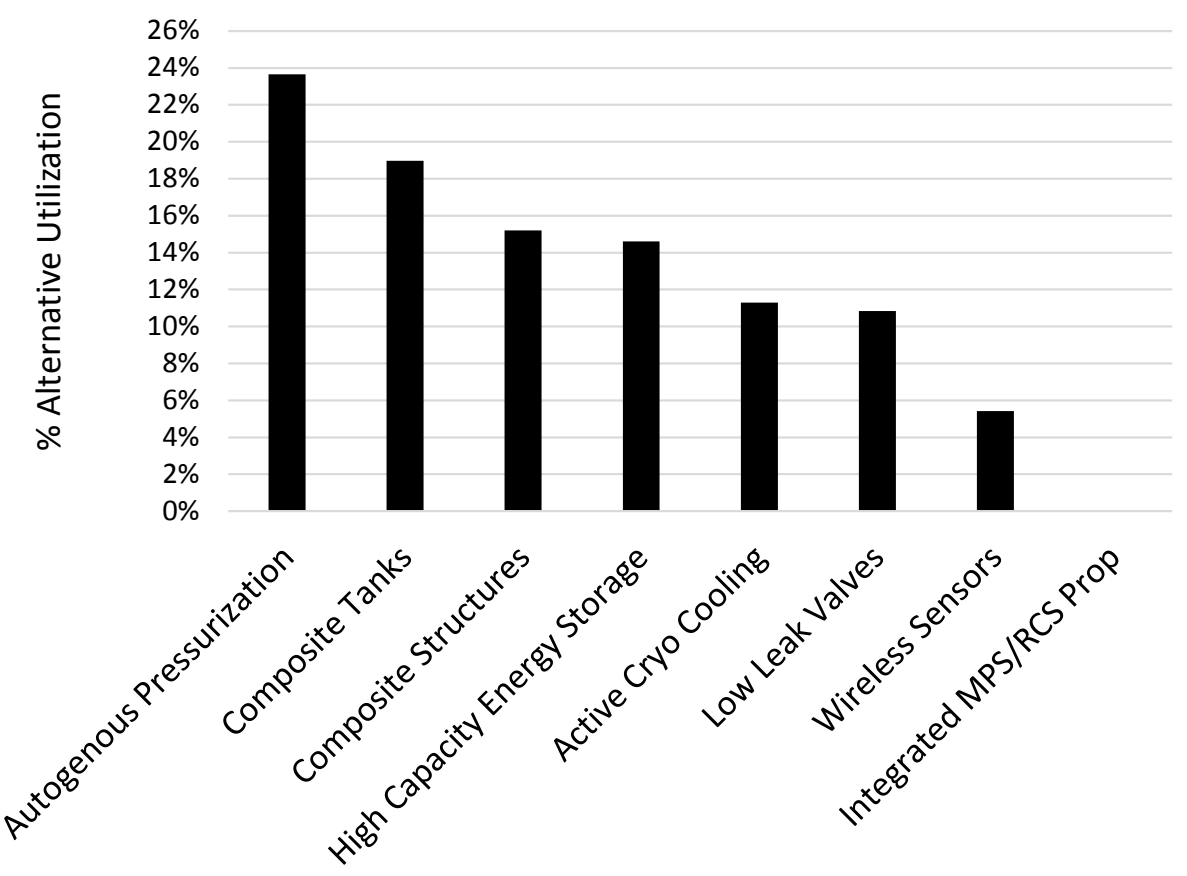

Fig. 9 Technology Utilization on the Pareto Front 


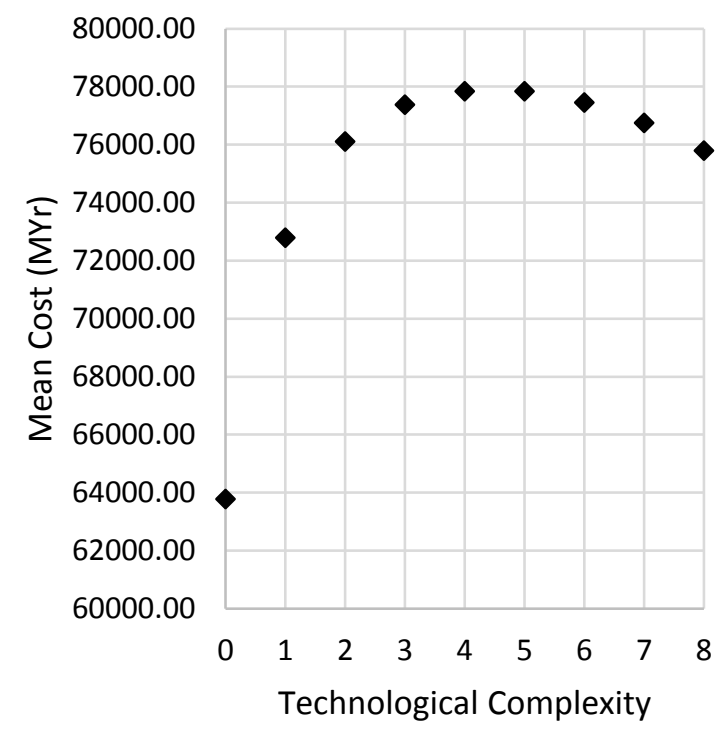

Fig. 10 Mean Cost of All Alternatives with Technological Complexity

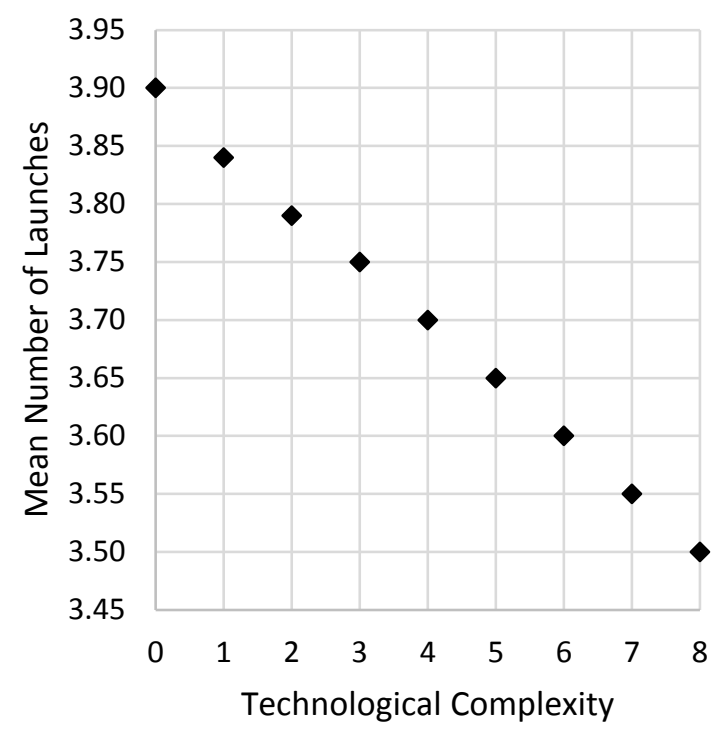

Fig. 12 Mean Number of Launches of All Alternatives with Technological Complexity

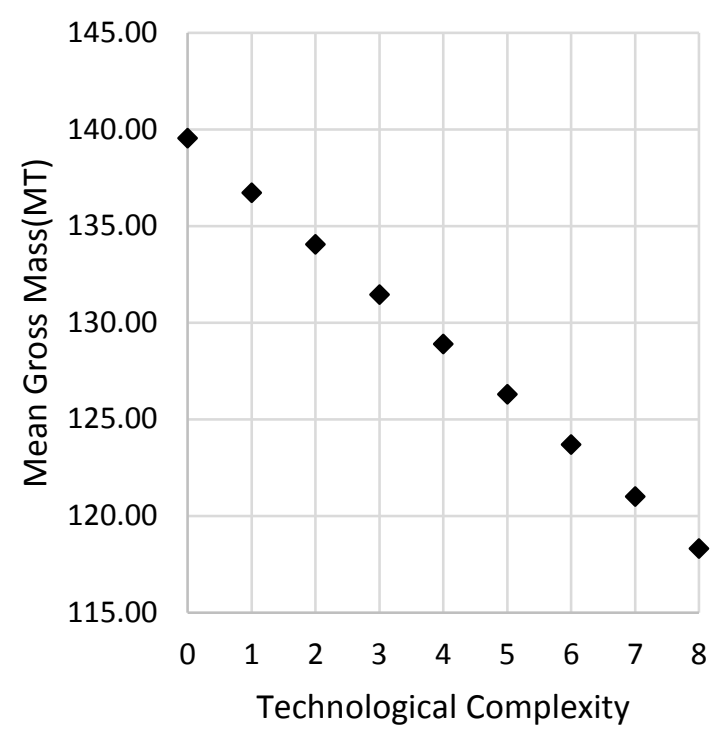

Fig. 11 Mean Gross Mass of All Alternatives with Technological Complexity

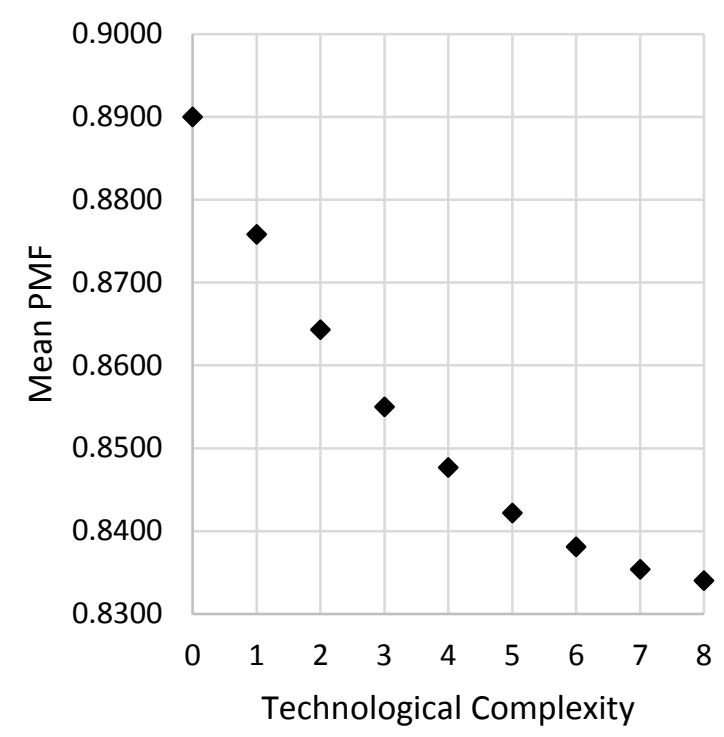

Fig. 13 Mean PMF of All Alternatives with Technological Complexity 


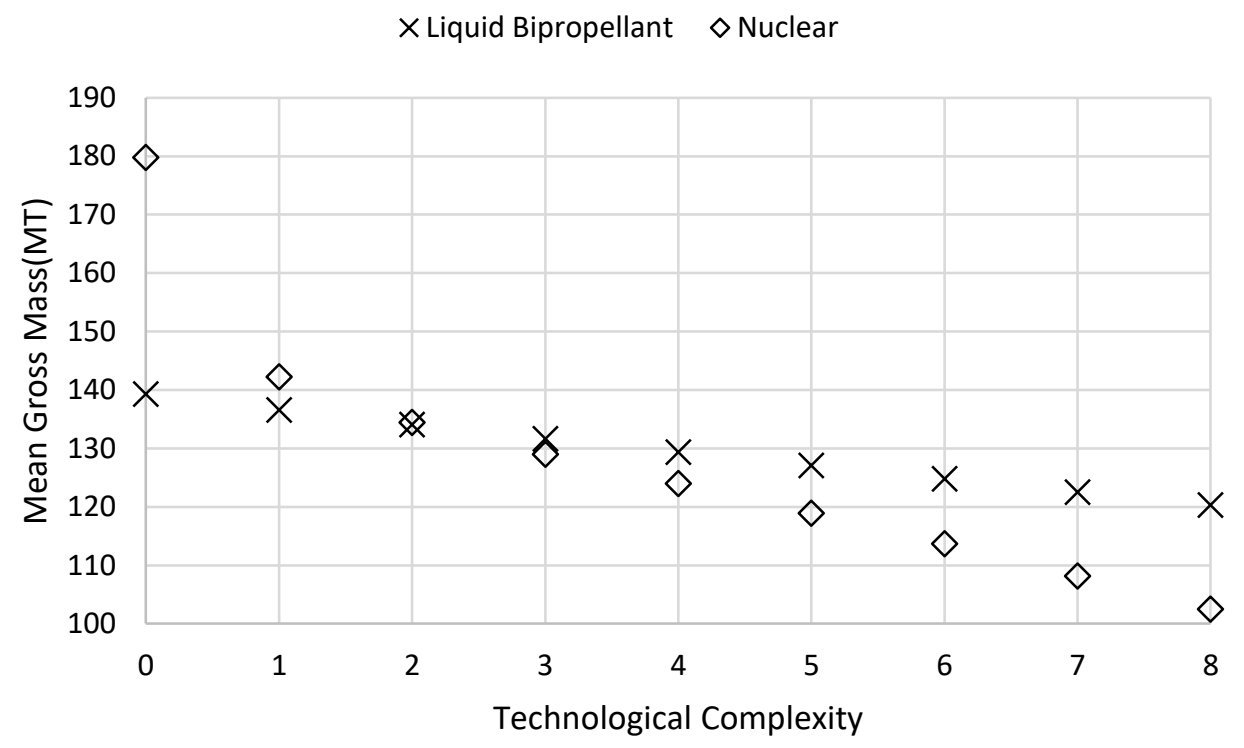

Fig. 14 Variation in Mean Gross Mass with Technological Complexity of Two Distinct Vehicle Groups 
Table 8 Mean Objective Metric Values for Each Architecture Option

\begin{tabular}{|c|c|c|c|c|}
\hline \multirow[b]{2}{*}{ Architecture Option } & \multicolumn{4}{|c|}{ Objective Mean } \\
\hline & Cost (MYr) & Mass (kg) & PMF & Launches \\
\hline \multicolumn{5}{|l|}{ Number of Stages } \\
\hline 1 & 42538.81 & 133551.03 & 0.875611 & 3.44799 \\
\hline 2 & 76262.12 & 127381.03 & 0.844251 & 3.70727 \\
\hline 3 & 110363.56 & 124935.20 & 0.827715 & 3.90317 \\
\hline \multicolumn{5}{|l|}{ MPS Class } \\
\hline Liquid & 74629.21 & 129066.21 & 0.875803 & 3.71198 \\
\hline Nuclear & 109762.44 & 121620.85 & 0.519790 & 3.45888 \\
\hline \multicolumn{5}{|l|}{ MPS Propellant } \\
\hline $\mathrm{LO}_{2} / \mathrm{LH}_{2}$ & 112521.29 & 120715.49 & 0.814451 & 3.49061 \\
\hline $\mathrm{LO}_{2} / \mathrm{LCH}_{4}$ & 97758.63 & 118277.95 & 0.878315 & 3.50034 \\
\hline NTO/MMH & 50600.27 & 128905.58 & 0.894645 & 3.72632 \\
\hline $\mathrm{LH}_{2}$ & 109762.44 & 121620.85 & 0.519790 & 3.45888 \\
\hline $\mathrm{N}_{2} \mathrm{H}_{4}$ & 53421.88 & 143490.05 & 0.899711 & 4.01934 \\
\hline \multicolumn{5}{|l|}{ RCS Propellant } \\
\hline $\mathrm{LO}_{2} / \mathrm{LCH}_{4}$ & 80786.69 & 132081.66 & 0.840288 & 3.72281 \\
\hline NTO/MMH & 75626.73 & 125698.07 & 0.854407 & 3.68163 \\
\hline $\mathrm{N}_{2} \mathrm{H}_{4}$ & 76427.51 & 128587.22 & 0.848772 & 3.68093 \\
\hline \multicolumn{5}{|l|}{ Tank Configuration } \\
\hline Stacked & 71312.02 & 124930.66 & 0.894892 & 3.64948 \\
\hline Disk & 79412.33 & 135029.36 & 0.848278 & 3.80210 \\
\hline Single & 109762.44 & 121620.85 & 0.519790 & 3.45888 \\
\hline \multicolumn{5}{|l|}{ Power System } \\
\hline Solar & 75252.95 & 126115.50 & 0.852191 & 3.65145 \\
\hline RTG & 79457.27 & 130946.72 & 0.844693 & 3.73493 \\
\hline \multicolumn{5}{|l|}{ MLI Layers } \\
\hline 10 & 78212.12 & 131596.42 & 0.848225 & 3.73974 \\
\hline 30 & 77251.87 & 128174.47 & 0.848915 & 3.69338 \\
\hline 50 & 76600.31 & 126036.12 & 0.848340 & 3.64968 \\
\hline
\end{tabular}

3. Technology Impacts

Table 9 Shift in Objective Metric Means Due to Technologies

\begin{tabular}{|l|rrrc|}
\hline & \multicolumn{4}{|c|}{ Mean Shift } \\
Description & Cost (MYr) & Mass (kg) & \multicolumn{1}{c|}{ PMF } & Launches \\
\hline Low Leak Valves & -3131.84 & -266.51 & -0.0001 & -0.01 \\
High Capacity Batteries & 8174.16 & -332.31 & 0.0009 & 0.00 \\
Composite Structures & 7488.31 & -1475.84 & 0.0038 & -0.01 \\
Composite Tanks & 7886.46 & -962.96 & 0.0027 & -0.01 \\
Integrated MPS/RCS & 9469.97 & 2417.35 & -0.0078 & 0.03 \\
Autogenous Pressurization & -2522.74 & -2136.48 & 0.0043 & -0.06 \\
Active Cryocooling & 24912.64 & -12323.25 & -0.0733 & -0.23 \\
Wireless Sensors & 8508.78 & -42.97 & 0.0001 & 0.00 \\
\hline
\end{tabular}




\section{Conclusion and Future Work}

Consideration of high-level SOS FOMs is critical in the proper design and evaluation of architectures and technologies at the subsystem-level. Typical FOMs utilized during subsystem-level design and technology evaluation can result in misleading conclusions at the SOS level of the design. One such example discussed is the use of PMF of a vehicle as a FOM. High-level architecture and technology options result in misleading conclusion regarding vehicle performance indicated by PMF. Increasing technological complexity lead to decreased vehicle performance measured by a decrease in vehicle PMF. However, this result is misleading due to how technologies interact with the design at the subsystem-level by reducing propellant mass requirements of the vehicle faster than the dry mass. Similar counterintuitive trends may be observed in other FOMs when performing subsystem-level sizing. Additionally, FOMs typically used for certain subsystem-level design, such as specific impulse for the propulsion system, may be poor FOMs for the high-level SOS.

Lack of understanding of knowledge of SOS architectures leads to increased risk due to cost and schedule overruns. This paper focused on brining detailed design knowledge forward in the conceptual design phase by integrating architecture analysis and technology evaluation at a subsystem-level. However, the large number of alternatives which exist due to combinatorial explosion typical in large SOS problems has yet to be addressed. Typical techniques for limiting this problem limit the information being brought forward in the conceptual design phase leading to potential loss of information. Additionally, further development on the integrated modeling and simulation tool, DYREQT, will help designers perform larger trade studies over a broader architecture and technology spaces to bring additional knowledge into the conceptual design phase.

\section{References}

[1] Fabrycky, W. J., and Blanchard, B. S., Life-cycle Cost and Economic Analysis, Prentice Hall, 1991.

[2] Emblemsvag, J., Life-Cycle Costing: Using Activity-Based Costing and Monte Carlo Methods to Manage Future Costs and Risks, John Wiley \& Sons, 2003.

[3] Havskjold, G., "Developing Innovative Products on Budget and On Schedule-Part 1: Identifying and Measuring Cost Drivers Correlates Technical Uncertainty With Rework Cycles," 45th AIAA/ASME/SAE/ASEE Joint Propulsion Conference \& Exhibit, 2009, p. 5436.

[4] Havskjold, G., "Developing Innovative Products on Budget and On Schedule-Part 2: Using Prodecol Charts to Control Development of an Innovative Advanced Technology System," 45th AIAA/ASME/SAE/ASEE Joint Propulsion Conference \& Exhibit, 2009, p. 5437.

[5] Havskjold, G., "Developing Innovative Products on Budget and On Schedule-Part 3: Generating the Prodecol Diagram," 45th AIAA/ASME/SAE/ASEE Joint Propulsion Conference \& Exhibit, 2009, p. 5437.

[6] NASA, "NASA Systems Engineering Handbook," Washington D.C., December 2017. NASA-SP-2016-6105 Rev2.

[7] Gass, S. I., Decision Making, Models and Algorithms, Krieger Publishing Comapny, 1991.

[8] Pugh, S., Total design: integrated methods for successful product engineering, Addison-Wesley Wokingham, 1991.

[9] Dieter, G. E., Engineering Design: A Materials and Processing Approach, McGraw-Hill series in mechanical engineering, McGraw-Hill, 2000.

[10] Sobek II, D. K., and Liker, J. K., “Another look at how Toyota integrates product development," Harvard business review, Vol. 76, No. 4, 1998, pp. 36-47.

[11] Mavris, D. N., DeLaurentis, D. A., Bandte, O., and Hale, M. A., "A stochastic approach to multi-disciplinary aircraft analysis and design," 36th Aerospace Sciences Meeting \& Exhibit, Reno, NV, 1998.

[12] Trent, D. J., "Integrated Architecture Analysis and Technology Evaluation for Systems of Systems Modele at the Subsystem Level," Ph.D. thesis, Georgia Institute of Technology, 2017. URL https://smartech.gatech.edu/handle/1853/59264

[13] Joint Chiefs of Staff, Joint Publication 1-02: Department of Defense Dictionary of Military and Associated Terms, U.S. Department of Defense, November 2010. As amended through 15 February 2016.

[14] IEEE Standards Board, "Systems and software engineering - Vocabulary," ISO/IEC/IEEE 24765:2010(E), 2010, pp. 20,357,360.

[15] International Council on Systems Engineering and Haskins, Cecilia, Systems Engineering Handbook: A Guide for System Life Cycle Processes and Activities, $3^{\text {rd }}$ ed., International Council of Systems Engineering, 2006. 
[16] U.S. Department of Defense, Defense Acquisition Guidebook, Defense Acquistion University, 2013.

[17] Dickerson, C., and Mavris, D. N., Architecture and Principles of Systems Engineering, CRC Press, 2010.

[18] Iacobucci, J. V., "Rapid Architecture Alternative Modeling (RAAM): A Framework for Capability-Based Analysis of System of Systems Architectures," Ph.D. thesis, Georgia Institute of Technology, 2012.

[19] Wertz, J., Everett, D., and Puschell, J., Space Mission Engineering: The New SMAD, Microcosm Press, 2011.

[20] NASA, "NASA Technology Roadmaps: Introduction, Crosscutting Technologies, and Index," NASA Office of the Chief Technologist, July 2015. Retrieved June 22, 2016, from http://www.nasa.gov/offices/oct/home/roadmaps/index.html.

[21] NASA, “NASA Systems Engineering Process and Requirements,” Washington D.C., October 2017. NPR 7123.1B.

[22] Allen, W. H., "Dictionary of Technical Terms for Aerospace Use,” NASA Headquarters, 1965. NASA SP-7.

[23] Brown, C. D., Elements of Spacecraft Design, AIAA Education Series, American Institute of Aeronautics and Astronautics, 2002.

[24] Joint Chiefs of Staff, Joint Publication 3-0: Joint Operations, U.S. Department of Defense, August 2011.

[25] Larson, W., and Pranke, L., Human Spacefight: Mission Analysis and Design, McGraw-Hill Companies, 1999.

[26] U.S. Air Force, "Early Systems Engineering Guidebook,", 2009.

[27] Sharma, J. L., "STASE: Set Theory-Influenced Architecture Space Exploration," Ph.D. thesis, Georgia Institute of Technology, 2014.

[28] Mavris, D., "Design of Experiments For Practical Applications in Modeling, Simulation, and Analysis," , 2011. Georgia Institute of Technology, Daniel Guggenheim School of Aerospace Engineering. Lecture.

[29] Mavris, D., and Griendling, K., "SoS Modeling and Simulation Fundamentals,", 2015. Georgia Institute of Technology, Daniel Guggenheim School of Aerospace Engineering. Lecture. 